\title{
Communication, Informational Literacy and Critical Thinking
}

\author{
Luís Miguel Cardoso
}

$\mathrm{PhD}$, Polytechnic Institute of Portalegre and CEC - University of Lisbon

Nuno Moura Silva

Master in Media and Society - Polytechnic Institute of Portalegre

\begin{abstract}
Being a citizen with literacy skills is fundamental. Nowadays we live in network and in the network. However, the fact that everything can be shared online entails some risks - both for users and for authors.. In order to deal with massive information and communication channels, having the competence and insight to be able to search and select the most credible information is a requirement and a fundamental competence in a networked society. In this paper we will reflect upon the concepts of communication, cyberculture, information literacy and critical thinking. In conclusion, it is demonstrated that information literacy is a key competence in contemporary society.
\end{abstract}

Keywords: Communication, Cyberculture, Information Literacy, Critical Thinking

\section{Introduction}

\section{Communication and cyberculture in contemporary society}

At the beginning of the 21 st century, a new stage of the information and communication society, which began with the popularization of the Internet in the 1980s, was debated and expanded with the development of portable computers, mobile phones, Internet access networks, Wi-Fi and bluetooth technology. All of this has revolutionized behavior in society, the way we experience urban space and the way we produce and consume information, subjects that are fundamental in cyberculture. Cyberculture eventually developed ubiquitously, making it not the user to move to the network, but the network that involves users and devices in a generalized connection.

The development of cyberculture occurs with the emergence of micro-computing in the 1970s, with technological convergence and the establishment of the personal computer (PC). Now, in the 21st century, with the development of laptops, mobile phones and other devices, what is in progress is a technological stage that is based on mobility. We are in the era of interactivity. Nowadays, we see the prefix "cyber" in everything: cyberpunk, cyberspace, cybercafé, cybercities, cyberarts, etc. Each expression forms, with its particularities, similarities and differences, the whole of cyberculture. (Lemos, 2004, 89).

The word ended up broadening the concept of culture through cyberculture, so it is important to emphasize that digital culture is only the natural evolution of culture produced by societies. It is differentiated by the fact that the data is stored in a place accessible to most people, which offers the possibility of socializing and communicating through social networks, emails, chats, forums and other platforms. This technological wave that crosses most of the social sectors lays the foundations of cyberculture, which, in turn, calls for the organization of new structures, mainly in relation to the way of organizing work, leisure and communication between people.

The contours of cyberculture are eventually defined as its use grows, as well as the access and efficiency of communication and information technologies. Still, broader definitions are lacking since one of the most important aspects of digital culture is its diversity. Because it is a contemporary event, theorists have not reached a consensus on the appropriate terminology to include the distinct characteristics of digital culture. Certain authors claim that we are in the middle of a digital revolution and that we have already entered a "Digital Age", also called the "Information Age". The same account with the aid of the technologies that enable the communication between people, production, storage and information sharing. The first scientific studies on cyberculture had as objective to describe the characteristics and to base the theoretical foundations of 
the subject. Researchers also elaborated studies on the cases of socialization motivated by information and communication technologies, in order to study the communities and the problems that involve the virtual identity. In recent years, researchers have devoted themselves to publishing critical works that address issues such as online interactions, digital discourses or digital inclusion and exclusion.

In fact, the influence that information and communication technologies have on societies and cultures is extraordinary. In 2004, André Lemos wrote that:

Cyberculture will be characterized by the formation of a society structured through a generalized telematic connectivity, broadening the communicative potential, providing the exchange of information in the most diverse forms, fomenting social aggregations. Cyberspace creates an operant world, interconnected to icons, portals, sites and homes pages, allowing the power of the emission to be placed in the hands of a young, tribal, gregarious culture that will produce information, add noise and collage, and throw excess into the system. ... perhaps we are looking for technologies for a new form of social aggregation (electronic, ephemeral and planetary). (Lemos, 2004, p.87)

Digital culture or cyberculture, whose boundaries are delimited as its use grows, requires broader definitions, given that one of its aspects is diversity. Given the novelty of this event, researchers have always found it difficult to reach consensus on terminology that best covers the diverse characteristics of digital culture. The other common names of cyberculture are: world culture, telecommunications culture, cyberspace culture and virtual culture. On the other hand, we all have a challenge in this cyberculture: how to understand the constant changes in information. In order to enhance our knowledge about this information society and its communication procedures, we need specific skills and competences that only literacies in general and information literacy in particular can provide.

\section{Literacies as means of understanding society}

Our current challenge in communication, in the universe of cyberculture and in the information society is to possess the means and instruments to understand the complexity of informational relations that surround us. For this understanding, Literacies are fundamental. In fact, as Jose Antonio Cordon Garcia (Lopes, 2016, xii) points out, we face several complex issues, which he calls "Gaps":

- Creative Gap. The authorship has substantially changed their condition, making greater use of the opportunities offered by new applications and software, many of which are freely available on the network. The new forms of authorship articulated by the blogosphere - self-publishing, transmedia, etc. - configure scenarios that will exclude those who do not know the tools of social character or who are incapable of building a solid digital identity, the first step towards the growth of virtual reputation.

- Information Gap. The information continues to grow exponentially in all its parameters. The extent of its impact is such that we are living in the age of big data, where only institutions and people capable of managing large numbers of data will have the ability to articulate a plausible and consistent discourse. Paradoxically, this situation has led to misinformation and under-utilization, especially by those who lack the skills necessary for their use. And in this context, inequalities reach a higher level, since information is the axis on which current society is articulated and a fundamental strategic element. Solving the problems associated with this deficit represents one of the greatest challenges for governments and cultural administrations around the world. The information gap is increasingly a digital gap, because the process of migration between analog and digital environments is increasingly pronounced, and it is necessary to respond to this problem in this double dimension.

- Cognitive Gap. Our ways of knowing, of mediating processes and thoughts, of interacting with the rest of society are radically transformed when the tools of communication and socialization change, when the ways of transmitting information change. The emergence of mobile technologies and their ability to combine diverse services, separated into differentiated channels, determined that access to knowledge is conditioned by the assimilation of practices related to the use of devices and applications, with digital reading and writing skills that allow the selection the problems inherent in a system in which the economy of care represents a mandatory variable. The cognitive gap is, in this sense, related to a kind of semantic breach, in which the ability to accurately and accurately capture the different contents is closely associated with the acquisition of skills that favor concentration and deep understanding. Moreover, in a context of excessive information, critical thinking and the need to selectively identify the competitive factors in any type of message represent another nonwaivable value of information literacy. 
The term "literacy" occurs in the late nineteenth century in Anglo-Saxon countries such as the United States of America and the United Kingdom. At first, the concept of literacy was limited to the most accessible interventions of reading, writing and calculation. In Portugal, since the word "literacy" was already a reality, it was in 1996 that the term "literacy" began to be used more regularly, following the study of Ana Benavente - Literacy in Portugal. In this way, literacy manifests itself in the ability to process information written in everyday life, and is therefore fundamental for educational success, for life in society, in work and in the exercise of citizenship, stimulating a critical and proactive spirit. In the 1980s, declining levels of illiteracy, proportional to large increases in schooling, failed to extinguish evidence: "countries such as France, the United States and Canada found that there were significant percentages of their population with difficulties in using written material" (Benavente, 1996, p. 4).

In the early 1990s, Canadian scholars defined literacy as the ability to process written information in everyday life. Thus "this definition of literacy goes beyond mere understanding and decoding of texts to include a set of information processing capabilities that adults use in solving tasks associated with work, personal life, and social contexts" (Benavente, 1996, p. 6). We can say that it is extremely important to develop intellectual tools that help people to select, evaluate, understand, reflect and communicate the knowledge resulting from the information collected. In this sense, there are studies that confirm that in the twentieth century "there was no statistically significant effect of literacy on social mobility. On the contrary, some individuals have achieved social ascension, but the large groups of the poor and discriminated have become even poorer"(Kleiman, 1998, 37).

\section{Information Literacy and Critical Thinking}

Information Literacy is currently one of the key concepts of this network society. Each citizen must possess skills in Information Literacy. The importance of access, use and production of scientific and academic knowledge, intrinsic to the course of the actors involved, in the teaching-learning process throughout life, is crucial in the information and knowledge society. The issue of access to credible information is something that students at different levels of education are confronted with, given the amount of information available, especially on the internet, as well as the diversity of tools - databases, digital libraries, virtual - developed platforms for our access. Given this reality, a scientific approach to information literacy is justified in order to provide the actors in this teaching / learning process with research, access and information selection skills.

The concepts of information literacy date back to the beginning of the last century, although the idea of helping people to find information has existed in the past with the possibility that it might already be a reality in the library of Alexandria. In 1853 the English priest, John Henry Newman, added the notion of Information Literacy in his work Idea of a University. 23 years later the american librarian Melvil Dewey defended that the school is a library and the librarian a teacher in the highest sense. In the last century, in the seventies, Paul Zurkowsky, (1981) president of the information industry association of the United States of America, in a proposal sent to the National Commission on Libraries and Information Science, refers for the first time to the expression Information Literacy. Zurkowsky proposed that the commission should focus on developing a national program to achieve universal information literacy in 1984. In 1976, Lee Burchinal at Texas A \& M University stated that to be literate in information, each person needs to be able to find and use the information you need to solve your problems and make efficient and effective decisions. Cees Hamelink and Major Owens argued that information literacy was an instrument of political emancipation. According to Owens, in addition to being necessary for greater efficiency and effectiveness of work, information literacy is necessary to ensure the democratic survival of institutions. All people are created equally, but voters with access to information are in a position to make smarter decisions than citizens who are informationally illiterate (Owens, 1976, p. 27).

In 2002, Christine Susan Bruce wrote about the conections between our society and the need for information literacy:

Information literacy is conceivably the foundation for learning in our contemporary environment of continuous technological change. As information and communication technologies develop rapidly, and the information environment becomes increasingly complex, educators are recognizing the needs for learners to engage with the information environment as part of their formal learning processes. IL is generally seen as pivotal to the pursuit of lifelong learning, and central to achieving both personal empowerment and economic development. Information literacy is a natural extension of the concept of literacy in our information society, and information literacy education is the catalyst required to transform the information society of today into the learning society of tomorrow. (Bruce, 2002, p. 3) 
Nowadays, we can quote as a possible basis the definition of Information Literacy that UNESCO formulated in 2008:

INFORMATION LITERACY means the set of skills, attitudes and knowledge necessary to know when information is needed to help solve a problem or make a decision, how to articulate that information need in searchable terms and language, then search efficiently for the information, retrieve it, interpret and understand it, organize it, evaluate its credibility and authenticity, assess its relevance, communicate it to others if necessary, then utilize it to accomplish bottom-line purposes; Information Literacy is closely allied to learning to learn, and to critical thinking, both of which may be established, formal educational goals, but too often are not integrated into curricula, syllabi and lesson plan outlines as discrete, teachable and learnable outcomes; sometimes the terms ". Information Competency," or "Information Fluency" or even other terms, are used in different countries, cultures or languages, in preference to the term Information Literacy. (Horton, 2008)

But the domain of information literacy implies working with an interconnected concept: critical thinking. Facione identifies expert consensus statement regarding critical thinking and the ideal critical thinker:

We understand critical thinking to be purposeful, self-regulatory judgment which results in interpretation, analysis, evaluation, and inference, as well as explanation of the evidential, conceptual, methodological, criteriological, or contextual considerations upon which that judgment is based. CT is essential as a tool of inquiry. As such, CT is a liberating force in education and a powerful resource in one's personal and civic life. While not synonymous with good thinking, CT is a pervasive and self-rectifying human

phenomenon. The ideal critical thinker is habitually inquisitive, wellinformed, trustful of reason, open-minded, flexible, fairminded in evaluation, honest in facing personal biases, prudent in making judgments, willing to reconsider, clear about issues, orderly in complex matters, diligent in seeking relevant information, reasonable in the selection of criteria, focused in inquiry, and persistent in seeking results which are as precise as the subject and the circumstances of inquiry permit. Thus, educating strong critical

thinkers means working toward this ideal. It combines developing CT skills with nurturing those dispositions which consistently yield useful insights and which are the basis of a rational and democratic society. (2015, p. 27)

Critical thinking is thus the ability to distinguish facts from fiction, develop an opinion on a particular topic or subject, and actually think about when it is that those who seek information will accept the "facts" and agree with the opinions they may or may not lead (McCormick, 1983). The main question turns out not to be the process of searching for information but rather what each person does with that information as soon as he finds it. A final report of the American Library Association's Presidential Committee on Information Literacy published in the late 1980s states that for an individual to be literate in information, he must be able to recognize when he needs that information and must be able to find it, evaluate and use the information you need efficiently. In the early 1990s Christina Doyle published the results of a Delphi study that increased the scope of information literacy definition. Participants in the study agreed that the basic definition of information literacy is the ability to search, find, analyze and use that information from different sources. The agreement went beyond this definition and the participants found similar views regarding the attributes of a person in information that would go through: recognize that accurate and complete information is the necessary basis for intelligent decision making; recognize the need for information; elaborate questions based on information needs; Identify potential sources of information; develop successful research plans; access information sources including those based on the computer and other technologies; evaluate the information; organize the information so you can apply it in a practical way; integrate new information into an existing body of knowledge; use information in critical thinking and problem solving (Doyle, 1992).

Jeremy J. Shapiro and Shelley K. Hughes (1996) referred in their book "Evaluating the Internet: a social progress matrix" seven dimensions of information literacy: (i) Literacy tools - Understanding technological information tools ; (ii) Literacy Resources - Understanding access methods and information resource formats; (iii) Social Structure of Literacy - to understand how information is produced and socially situated; (iv) Research in Literacy - use relevant technological information tools; (v) Publication of Literacy - to promote and investigate publications and ideas in multimedia formats; (vi) Emerging technologies - Using emerging information technologies; (vii) Critical literacy - critically assess the capabilities and limits of information technologies.

The Association of College and Research Libraries defines Information Literacy as a set of vocations that each person must possess to recognize when they need information and how they must find the information they need, how to examine it and how to use it effectively. Information literacy includes information interests and needs as well as the ability to identify, 
locate, evaluate, organize and efficiently create, use and communicate information to solve issues or problems. It is a prerequisite for effective contribution to the information society and is part of the basic human right of lifelong learning.

Information literacy can cover students in research or research issues that make them want to become better at developing their minds and learning in general. Studies on the professional use of information resources in specific areas such as health emphasize the importance of teaching information literacy as a way to determine the advantages and risks of using open resources such as general searches on Google and the importance of use of reference resources. UNESCO (2008) also considers information literacy as fundamental to understanding these subjects in nowadays society and the challenges of today's communication:

Increasingly, the concept of information literacy is considered as crucially important to enable people to deal with the challenge of making good use of information and communication technology. Indeed, governments, intergovernmental and non-governmental organizations, academia, civil society and the private sector have all come to the conclusion that computers, the Internet, and hand-held wireless devices are driving today profound changes in the way pictures, voice, and information are being created, transmitted, accessed and stored. But they also conclude that learning computer and media technologies are not enough if nations, institutions and individuals are to reap the full benefits of the global knowledge societies. In this context, 'information literacy has become a new paradigm in the information and communication landscape. Sometimes other synonyms such as 'information fluency' or 'information competency' are being used instead. How the concept is defined, understood and applied differs at this early stage in the concept's development from one nation, one culture or one linguistic group to another. However, the Alexandria Proclamation adopted by the High Level Colloquium on Information Literacy and Lifelong Learning in November 2005 defines information literacy as a mean to "empower people in all walks of life to seek, evaluate, use and create information effectively to achieve their personal, social, occupational and educational goals". In the digital age, what information literacy means is that understanding technologies is not enough. What everyone must also do is learn how to utilize those incredibly diverse and powerful technologies efficiently and effectively to search for, retrieve, organize, analyze, evaluate information and then use it for specific decision-making and problem-solving ends. (Horton, 2008)

Furthermore, Bruce (2004) underlines the need to organize information literacy programs as follows:

In any educational sector, there are four critical components of an information literacy program:

1. Resources to facilitate the learning of specific skills, eg web based information skills enhancement packages and other point of need, or self paced instruction.

2. Curriculum that provides the opportunity to learn specific skills, either early in a course or at point of need, (from selfpaced packages, peers, lecturers, librarians) [integrated].

3. Curriculum that requires engagement in learning activities that require ongoing interaction with the information environment [embedded].

4. Curriculum that provides opportunities for reflection and documentation of learning about effective information practices [embedded].

The first of these represents the resource base that supports learning skills undepinning information literacy, the second represents curriculum integration, and the latter two represente what is better described as 'embedded' information literacy education. In all sectors, curriculum development, including course approval and review processes, maybe used to monitor the inclusion of information literacy in curriculum.

\section{Conclusion}

In 1999 the first step towards the renewal of the European university system was taken. The Bologna Declaration was preceded by the Sorbonne Declaration a year earlier and the working documents of Prague (2001) and Berlin (2003) which set out the strategies for the development of a European quality university and with it the creation of the European Area of Higher Education (EHEA). The entire Bologna process was aimed at training students adapted to the requirements of international competitiveness with the aim of spreading employment, fostering a better performance of European professionals. In the light of this process the university introduces a set of measures intended to increase the level of flexibility, adaptability and efficiency of Europeans. 
Bologna represents not only increasing student participation in the method of learning, restructuring the form and quantity of training time, but more significant is the change that supposes from the methodological point of view. With this new model of Bologna means that the subjects are articulated in the base of the development of competences, rejecting a model of teaching - learning in which what is important is only the content. States need a learning based on competences, that is, a set of knowledge, learned with the aim of knowing how to put them into practice and structured, at the same time, with the development of modes, such as responsibility, communication, flexibility or autonomy.

In this context, the training of students, centered on the acquisition of competences, becomes inseparable from the use of critical thinking in relation to contemporary society and to informational challenges. In addition to this critical thinking, information literacy emerges, essential for the codification and decoding of the universe of messages that surround us. Information Literacy is a fundamental theme in the present information and knowledge society. The amount of information that is available is increasing and this is increasingly accessible. Along with the increase in the amount of information, there has been an increase in the information in different formats of the written text. Increasing the speed of data transmission has increasingly facilitated the use of image, audio and video. The Internet has played an elementary role in these same transformations. With the emergence of mobile communications, where the Internet is also present information increasingly assumes a ubiquitous function. In this vastness of information it is extremely important to know what is important information, how to find it and how to learn to deal with it properly.

In short, students and teachers live today the challenge of articulating communication, critical thinking and information literacy, to proceed to a true and full understanding of the world around us.

\section{References}

[1] Benavente, Ana (1996) A Literacia em Portugal. Resultados de uma pesquisa extensiva e monográfica (coord.), Lisboa, Fund. Calouste Gulbenkian

[2] Bruce, Christine (2004) Information Literacy as a Catalyst for Educational Change. A Background Paper . In Danaher, Patrick Alan, Eds. Proceedings "Lifelong Learning: Whose responsibility and what is your contribution?", the 3rd International Lifelong Learning Conference, pages pp. 8-19, Yeppoon, Queensland.

[3] D.C: National Commission on Libraries and Information Science, 1974. Available at: http://www.eric.ed.gov/PDFS/ED100391.pdf

[4] Doyle, C. (1992). Outcome measure for information literacy within the National Educational Goals of 1990. Final report to the National Forum on Information Literacy. Flagstaff:AZ, NFIL

[5] Facione, P. (2015) Critical thinking: What it is and why it counts. California Academic Press insightassessment.com

[6] Horton, F. W. (2008) Understanding information literacy: a primer. Paris: UNESCO

[7] Kleiman, Ângela (1998) Ação e mudança na sala de aula: uma nova pesquisa sobre letramento e interação. In: ROJO, R. (org.).Alfabetização e letramento: perspectivas lingüísticas. Campinas: Mercado de Letras

[8] Lemos, André (2004) Cibercultura, tecnologia e vida social na cultura contemporânea. Porto Alegre: Sulina, 2a. ed.

[9] Lopes C. et alii (org) (2016) Literacia da informação em contexto universitário. Lisboa: ISPA

[10] McCormick, Mona (Summer 1983) Critical thinking and library instruction. RQ 22:339-342.

[11] Owens, M. R. (1976) State government and Libraries. Library Journal, New York, v. 101

[12] Shapiro, J. and Hughes, Shelley K. (1996). "Evaluating the Internet: a social progress matrix", (co-author with Shelley K. Hughes) in Proceedings of INET ' 96 (Montreal: Internet Society, 1996)

[13] Shapiro, Jeremy J. and Hughes, Shelley K. (March/April 1996) Information literacy as a liberal art. Educom Review 31(2) http://www.educause.edu/pub/er/review/reviewArticles/31231.html

[14] Theoretical Gap. Library Journal, New York, v. 106, n. 13, p.1381-1384, July _. Information services environment relationships and priorities. Washington,

[15] Zurkowski, P. G. (1981) The Library Context and the Information Context: Bridging the 